employ a societal perspective in addition to any other perspective utilised (e.g. individual, third-party payer, government).

Affordability is simply the question of whether the available resources are sufficient to meet the costs of implementing and maintaining the proposed interventions.

Cost modelling studies do not directly address the above issues, but they can help identify the main drivers of costs and assess the effect of interventions on broader costs (e.g. Carr et al, 2004).

\section{There is a demonstrably high level of expenditure on psychosis in Australia and a more rational basis for resource allocation is required, driven primarily by treatment efficiency and equity considerations.}

\section{Equity and feasibility}

The principle of equity has to do with the extent to which a given society may seek preferential allocation of resources for socially and economically disadvantaged groups, marginalised or less powerful groups, remote or isolated communities, and diseases that may be conspicuous in the community or associated with high levels of disability (e.g. psychoses). Feasibility refers to whether the intervention falls within the existing or readily achievable range of human expertise or technological capacity.

\section{Other issues}

H aving thus established a priority list of potential evidencebased, cost-effective interventions, assessed their affordability, and addressed questions of equity and feasibility, there are further issues to be addressed. Structural adjustments are necessary to permit the flexible allocation of 'discretionary' expenditure (e.g. in Australia, shifting from long-term hospitalisation to supported community accommodation in the treatment of psychosis). 0 ther implementation issues include training, administration, uptake by clinicians, and intangible or hidden costs. Programmes are necessary to increase clinicians' and administrators' awareness of efficient interventions, to improve the therapeutic skills of clinicians, and to motivate them to provide the identified interventions. Motivation to deliver the interventions can be enhanced through the provision of incentives. These may include a combination of financial rewards and disincentives, prestige enhancement or promotion, performance reviews, and feedback of information concerning effectiveness and efficiency. Implementation should also be monitored at the individual, health system and government levels so that timely adjustments can be made.

\section{Conclusions}

There is a demonstrably high level of expenditure on psychosis in Australia and a more rational basis for resource allocation is required, driven primarily by treatment efficiency and equity considerations. We also contend that many of the principles outlined above are not just applicable to the psychoses but could usefully inform decisions about resource distribution in mental health services generally.

\section{References}

Andrews, G., Sanderson K., Corry, J., et al (2003) Costeffectiveness of current and optimal treatment for schizophrenia. British Journal of Psychiatry, 183, 427-435.

Andrews, G., Issakidis, C., Sanderson K., et al (2004) Utilising survey data to inform public policy: comparison of the costeffectiveness of treatment of ten mental disorders. British Journal of Psychiatry, 184, 526-533.

Carr, V. J., N eil, A. L., Halpin, S. A., et al (2003) Costs of schizophrenia and other psychoses in urban Australia: findings from the Low Prevalence (psychotic) Disorders Study. Australian and New Zealand Journal of Psychiatry, 37, 31-40.

Carr, V. J., Lewin, T. J., N eil, A. L., et al (2004) Premorbid, psychosocial and clinical predictors of the costs of schizophrenia and other psychoses. British Journal of Psychiatry, 184, 517-525.

ablensky, A., McGrath, J., Herrman, H., et al (2000) Psychotic disorders in urban areas: an overview of the methods and findings of the study on low prevalence disorders. Australian and New Zealand Journal of Psychiatry, 34, 221236

$\mathrm{N}$ eil, A. L., Lewin, T. J. \& Carr, V. J. (2003) Allocation of resources and psychosis. Australian and $\mathrm{New} Z$ Zealand Journal of Psychiatry, 37, 15-23.

\title{
Psychiatric senvices in the fifth year of health care reform in Poland
}

\section{Wanda Langiewicz and Elzbieta Slupczynska-Kossobudzka}

Department of Health Care Organisation, Institute of Psychiatry and Neurology, Warsaw, Poland, email langiew@ipin.edu.pl

hanges in the Polish health care system, introduced by a Parliamentary Act in 1999, resulted from an urgent need for a more effective provision of health services, which were held in poor esteem by the public. Public expenditure on health care at the time of the reform was equivalent to $4.19 \%$ of gross national product, or US\$363 at purchasing power parity (PPP) per capita. This amount was considerably lower than in the most developed countries (i.e. members of the Organisation for 
Economic Cooperation and Development, OECD). The reformers' main modification consisted of replacing state financing of health services with insurance-based financing. Statutory health insurance covers $99.4 \%$ of Poland's 38.2 million citizens. The insurance fee is to be increased from $7.0 \%$ of personal income at the beginning of the reforms to $9.0 \%$ (at present it has reached $8.25 \%$ ). The aim was also to achieve relatively stable health care expenditure, independent of the annual political budget allocation. A special administrator was appointed for the Sickness or $\mathrm{N}$ ational Health Fund and was authorised to contract for health services. These marketoriented developments were paralleled by the implementation of special programmes, financed from the Ministry of $\mathrm{Health}$ budget, which were aimed at restructuring health care facilities.

Since the earliest days of the reforms, attention has been drawn to the problem of so-called 'blurred responsibility' - namely, it was difficult to specify the extent of responsibilities and mutual relations between the state administration units, regional governments, payers, service providers and patients. Another objection concerned confusion about how public resources were to be distributed among the regions and health care areas. Disproportionate allocation, in many cases, limited access to some specialists and health care facilities. These difficulties were usually attributed to an insufficient supply of financial resources, due to an insufficiently low health insurance rate, as well as poor management. Reimbursement rates offered in the contracts for health services frequently did not cover the real costs. In turn, this resulted in many health care facilities experiencing growing debts and financial liquidity problems.

\section{The effect on psychiatric care}

Although the above problems pertained also to the provision of psychiatric care, the reforms were expected to aid the development of community-based psychiatric care in Poland. The following are the main achievements of the past 5 years.

o Sixteen psychiatric wards have been established within general hospitals, which has increased the proportion of this category of bed from 13\% to $15 \%$ (the latter figure represents a total of 5000 beds).

o More than 50 day hospitals for psychiatric patients have been opened (an increase of $45 \%$ ).

o In large mental hospitals, the process of psychiatric bed reduction has continued (their number has decreased by 3000 , or $17 \%$ ).

o There has been a restructuring of mental hospitals less expensive units providing nursing-therapeutic care have been created.

O The number of psychiatric out-patient clinics has been increased by $50 \%$, to some 950 .

In general, the above changes are in line with the $\mathrm{N}$ ational Mental $\mathrm{H}$ ealth Programme set up by a team from the Institute of Psychiatry and $N$ eurology.
Financial resources

The popular belief that success of the health care reform programme depends largely on the financial resources allotted seems to be correct. Public expenditures on health care have increased since the pre-reform period insufficiently in relation to needs, the more so as a large proportion of the increment has been spent on medication. Psychiatric care is also affected by the scarcity of resources. At present about $€ 220$ million is allotted to psychiatric care provision (without the costs of medication reimbursement), which is about $3.4 \%$ of all health service expenditure. The estimated shortfall of 15-20\% significantly reduces the chances of attaining the planned targets. Any large-scale implementation of the communitybased model of psychiatric care would require considerable additional funds.

\section{Medical priorities}

The (frequently modified) reform regulations lack mechanisms to link health policy targets to payers' decisions. The Mental Health Programme outlined the major targets and tasks of psychiatric care but has no statutory power, so the interests of psychiatry have usually been secondary to those of other areas of health care (which have a higher social and medical profile). The majority of the changes noted above in the psychiatric infrastructure have been made in response to opportunities arising after the reform implementation, rather than being planned.

\section{Out-patient and day patient care}

The allocation of funds to cheaper alternatives than psychiatric hospitalisation (i.e. day hospitals and psychiatric out-patient clinics) is beneficial for the payer, and is in tune with reform priorities. The $50 \%$ increase in the number of psychiatric out-patient clinics noted above has led to a $63 \%$ increment in the number of treated patients. How ever, this success was achieved at the cost of a welldeveloped network of such clinics that existed before the reform, some of which were divided into smaller and understaffed units. Since traditional bonds between hospitals and out-patient clinics have been disrupted in some regions, and after-care continuity has deteriorated. There has been a marked increase in psychiatric day hospitals and alcohol and drug treatment day centres, resulting from the payer's decision to promote these cheaper forms of care, which are easily located on the premises of existing health care facilities. Accessibility of day patient services has therefore improved mostly in large cities, where it is also easier to find appropriate staff.

\section{In-patient care}

In-patient psychiatric care was a particular challenge to the reformers, since in some regions there were too many hospital beds while in others there was a scarcity of them. The replacement of large mental hospitals by psychiatric wards within general hospitals was financially and socially difficult. Because they had only modest budgets, the regional governments, which formally owned the mental hospitals, were unable to support the planned modernisation. $N$ one the less, general hospitals did create new
The $50 \%$ increase in the number of psychiatric outpatient clinics has led to a $63 \%$ increment in the number of treated patients. However,

this success was achieved at the cost of a well developed

network of such clinics that existed before the reform,

some of which were divided into smaller and understaffed units.

In-patient psychiatric care was a particular challenge to the reformers, since in some regions there were too many hospital beds while in others there was a scarcity of them. 
psychiatric wards. Their establishment was aided, on the one hand, by financial support from the so-called restructuring programmes and, on the other hand, by the payer's readiness to contract for such psychiatric services.

A detailed cost-effectiveness analysis revealed that in large mental hospitals beds were not fully used, too many patients were hospitalised for social reasons, and there was a liberal attitude to wards treatment duration. 0 ver the 5 years of reform, the number of excess beds has been reduced and the remaining ones have been better used. The average treatment duration has been shortened by 12 days, to 35 days.

\section{After-care}

While after-care in sheltered housing and hostels is desirable, there are insufficient funds for its general implementation. Moreover, funds for this purpose are regarded as improving quality of life, which does not constitute a priority within the tight constraint on budget limits.

Hypothecated funding

It should be noted that the $\mathrm{N}$ ational $\mathrm{H}$ ealth Fund formally allotted special resources to psychiatric care for the first time in the 2004 financial plan. This is an encouraging move and will improve the regional distribution of funds. There were also reforms in contracting principles, including prescriptive conditions for psychiatric service provision, developed by our Institute and approved by the psychiatric community in general.

\section{Further reading}

Langiewicz, W. \& Slupczynska-Kossobudzka, E. (2000) O rganization and financing of mental health care in Poland. Journal of Mental Health Policy and Economics, 3, 77-81.

\section{Contributions to}

the country profile section are welcome: please contact Shekhar Saxena (email saxenas@who.int).

\section{A 1997 survey} conducted by the National Statistical Coordination Board showed a poverty incidence of $31.8 \%$. If this rate is applied to the 2000 population census report then, for that year, over 24 million Filipinos can be considered poor and therefore likely to be at high risk in terms of health status.

\title{
The state of mental health in the Philippines
}

\author{
Udgardo Juan L. Tolentino, Jr
}

Executive Assistant, National Program for Mental Health and Substance Abuse, Department of Health, Philippines, email edtol.md@pacific.net.ph

$$
\text { Trons }
$$
he Philippines, known as the Pearl of the $O$ rient, is an archipelago of 7107 islands, bounded on the west by the South C hina Sea, on the east by the Pacific $O$ cean, on the south by the Sulu and Celebes Sea, and on the north by the Bashi Channel. The northernmost islands are about $240 \mathrm{~km}$ south of Taiwan and the southernmost islands approximately $24 \mathrm{~km}$ from Borneo. The country has a total land area of some $300000 \mathrm{~km}^{2}$. It is divided into three geographical areas: Luzon, Visayas and M indanao. It has 17 regions, 79 provinces, 115 cities, 1495 municipalities and 41956 barangays (the smallest geographic and political unit). It has over 100 ethnic groups and a myriad of foreign influences (including Malay, Chinese, Spanish and American).

The last official census (2000) put the population at 76498 735. However, the $N$ ational Statistics $O$ ffice Population Projections Unit estimated it to be 81081457 in 2003. The annual population growth rate (1995-2000) is 2.36\% (a reduction from the 1980s). The population is young: $38 \%$ are under 15 years old and only $3.5 \%$ over 65 years. Most $(83 \%)$ of the population is $\mathrm{C}$ atholic. The literacy rate is fairly high at $95.1 \%$ for males and $94.6 \%$ for females, which possibly accounts for the facility with which Filipinos find work abroad. Labour is, in fact, a prime export of the country.

More than half of the Philippine population resides in Luzon. W ithin that area, the $\mathrm{N}$ ational C apital Region (N CR) has $12.9 \%$ of the national population (9 906048 inhabitants in $61728 \mathrm{~km}^{2}$ of land). It is composed of 13 cities,
4 municipalities and 1693 barangays. Three cities in the NCR have emerged as the most populous: Q uezon City, Manila and Caloocan, which have populations of 2.17 million, 1.58 million and 1.18 million, respectively. Among the provinces, Pangasinan is the most populous, with 2.43 million, followed by Cebu, with 2.37 million and Bulacan, with 2.23 million people.

O pportunities brought about by economic development vary from region to region and this has affected internal migration. In 1980 , about $37 \%$ of the total population resided in urban areas. By 1990, the urban proportion of the population had increased to $49 \%$, with the N CR getting the bulk of this population increase. By the year 1995 , more than half of the population (54\%) lived in urban areas and this proportion increased further, to $59 \%$, by the end of 2000 .

A 1997 survey conducted by the $\mathrm{N}$ ational Statistical Coordination Board showed a poverty incidence of $31.8 \%$. If this rate is applied to the 2000 population census report, then, for that year, over 24 million Filipinos can be considered poor and therefore likely to be at high risk in terms of health status.

\section{General health care}

Health status indicators sourced from the $\mathrm{N}$ ational Statistics 0 ffice are shown in Table 1.

The available health resources are not only inadequate but also inequitably distributed. There are 548 government and 1146 private hospitals; the government 